• 研究简报・

\title{
极小种群野生植物黄梅秤锤树群落结构与动态
}

\author{
王世䑣 1,2 吴 浩 1,2 刘梦婷 1,2 张佳金金 ${ }^{1,2}$ 刘检明 1,2 孟红杰 ${ }^{1}$ \\ 徐耀粘 ${ }^{1}$ 乔秀娟 ${ }^{1}$ 魏新增 ${ }^{*}$ 卢志军 $^{1}$ 江明喜 ${ }^{1}$
}

1 (中国科学院水生植物与流域生态重点实验室, 中国科学院武汉植物园, 武汉 430074)

2 (中国科学院大学, 北京 100049)

摘要: 本文以极小种群野生植物黄梅秤锤树(Sinojackia huangmeiensis)当前唯一的野生种群为依托建立了 1 ha的固 定样地, 研究了黄梅秤锤树野生植物群落的物种组成、优势种的径级结构、黄梅秤锤树的空间分布格局、种内与 种间空间关联性和种群更新特征。样地内共记录到胸径 $\geq 1.0 \mathrm{~cm}$ 的木本植物 31 种, 隶属于 21 科28属。群落更新良 好, 样地中所有 1,225 株个体中小径木占比为 $67.18 \%$ 。群落优势种为麻栋(Quercus acutissima)、枸骨(Ilex cornuta)、 朴树 (Celtis sinensis)和黄梅秤锤树。麻柇的径级结构呈单峰型, 为衰退型种群; 枸骨、朴树和黄梅秤锤树的径级结 构呈倒“J”型或偏倒“J”型, 表明更新良好。黄梅秤锤树的空间分布格局在小尺度上呈聚集分布, 在大尺度上呈随机 或均匀分布, 并且与其他 3 个优势种(麻柇、枸骨、朴树)在空间上主要呈负关联性。黄梅秤锤树的成树和幼苗、幼 树和幼苗都是在小尺度上呈负关联性，在大尺度上关联性不显著，而成树和幼树在整体上关联性不显著。黄梅秤 锤树的萌萺现象非常明显, 萌菜数与母株胸径具有极显著的正相关性 $\left(R^{2}=0.330, P<0.001\right)$, 萌摹率与相对幼苗 密度具有极显著的负相关性 $\left(R^{2}=0.438, P<0.001\right)$ 。总体来说, 高比例的小径木和普遍的种间负关联均表明该群落 处于演替的早中期, 物种组成和群落结构还未达到稳定阶段。作为长江中下游冲积平原区具有代表性的残存风水 林, 该野生植物群落在生物多样性维持和珍稀植物保护方面具有重要的作用, 应加强保护和管理。

关键词: 物种组成; 径级结构; 点格局分析; 风水林; 极小种群野生植物; 黄梅秤锤树; 就地保护

\section{Community structure and dynamics of a remnant forest dominated by a plant species with extremely small population (Sinojackia huangmeiensis) in central China}

Shitong Wang ${ }^{1,2}$, Hao $\mathrm{Wu}^{1,2}$, Mengting $\mathrm{Liu}^{1,2}$, Jiaxin Zhang ${ }^{1,2}$, Jianming Liu ${ }^{1,2}$, Hongjie Meng ${ }^{1}$, Yaozhan $\mathrm{Xu}^{1}$, Xiujuan Qiao ${ }^{1}$, Xinzeng $\mathrm{Wei}^{{ }^{1 *}}$, Zhijun $\mathrm{Lu}^{1}$, Mingxi Jiang ${ }^{1}$

1 Key Laboratory of Aquatic Botany and Watershed Ecology, Wuhan Botanical Garden, Chinese Academy of Sciences, Wuhan 430074

2 University of Chinese Academy of Sciences, Beijing 100049

\begin{abstract}
In China, Sinojackia huangmeiensis is among the 120 plant species with extremely small populations (PSESP), with only one extant wild population located at the lakeside of the Longgan Lake, central China. Here, we followed the field protocol of the 50-ha permanent forest plot on the Barro Colorado Island in Panama to census all free-standing woody species $\geq 1 \mathrm{~cm}$ diameter at breast height (DBH) in a 1-ha plot established in a lowland fengshui forest dominated by $S$. huangmeiensis. We recorded a total of 1,225 living individuals, belonging to 31 species, 28 genera and 21 families. Individuals with $\mathrm{DBH}<7.5 \mathrm{~cm}$ accounted for $c a .67 \%$ of all individuals, indicating good natural regeneration in the community. The most dominant species were Quercus acutissima, Ilex cornuta, Celtis sinensis, and S. huangmeiensis. Quercus acutissima showed a single peak pattern of diameter class distribution, while I. cornuta, C. sinensis, and S. huangmeiensis showed a reverse "J" shape or a partial reverse "J" shape. S. huangmeiensis showed aggregated distribution at small spatial scales and random or uniform distributions at large scales. Individuals of S. huangmeien-
\end{abstract}

收稿日期: 2018-02-11; 接受日期: 2018-04-02

基金项目: 国家重点研发计划项目(2016YFC0503105)和国家自然科学基金(31470515)

* 通讯作者 Author for correspondence. E-mail: xzwei@wbgcas.cn 
sis were negatively associated with the other three dominant species. Seedlings of S. huangmeiensis were negatively associated with both conspecific saplings and adults at small scales, but showed no correlation at other scales. There was a significantly positive correlation between sprout number and DBH of $S$. huangmeiensis $\left(R^{2}=0.330, P<0.001\right)$, whereas ratio of sprout and relative seedling density showed a negative correlation $\left(R^{2}=0.438, P<0.001\right)$. In general, high percentage of small-sized individuals and interspecific negative associations suggested that this plant community is still at an early-to-middle stage of succession. The remnant fengshui forests in the lowland plains of the middle and lower reaches of the Yangtze River are important for their roles in the conservation of biodiversity and endangered plants and should therefore be protected and well-managed.

Key words: species composition; diameter class structure; point pattern analysis; fengshui forest; plant species with extremely small populations; Sinojackia huangmeiensis; in situ conservation

群落物种组成和空间分布格局是生态系统功 能和过程的基础，是一定区域内种内、种间关系以 及物种与环境之间长期相互作用的结果(梁爽等, 2014; 刘艳会等, 2017)。群落物种组成和优势种空 间分布格局研究可以为物种共存和生物多样性维 持机制的研究提供重要信息(Tilman et al, 2006)。物 种空间分布格局可以反映不同种群个体在群落中 的分布类型以及物种间的相互关系(Dale, 1999; John et al, 2007)。1977年, Ripley提出了点格局分析 理论(Ripley, 1977), 实现了从不同尺度分析植物群 落的生态学特性。近年来, 该方法被广泛应用于物 种空间分布格局的研究中(解传奇等, 2015; 刘旻霞, 2017; Omelko et al, 2018)。种间关联分析可以确定 群落内物种间的相互作用和生境分异, 而且可以确 定群落演替的阶段(Wiegand et al, 2007; 祝燕等, 2011; 农友等, 2015)。种内关联可以用来描述同一 物种不同生长阶段的个体在空间分布上的关系, 进 而揭示不同年龄阶段个体间的功能关系和相互作 用(王否等, 2010; 高福元等, 2014)。群落优势种种 群径级结构和萌生特性的分析不仅可以揭示物种 的种群动态和更新策略, 还可以预测群落演替的趋 势(达良俊等, 2004; Wei et al, 2015)。

然而, 前人对于植物群落组成和空间分布的研 究多为山地原生林或山地次生林, 人为干扰相对较 小。平原低地残存的次生林(如风水林)受人为活动 影响较大, 面积逐渐减小, 区域植被遭受到不同程 度的破坏, 但这类残存的野生植物群落中仍然具有 较高的生物多样性, 并且对珍稀特有植物和物种多 样性的保护具有重要作用(Aerts et al, 2006; 杨永川 等, 2007; Tang et al, 2013)。然而, 目前对该类型群 落的物种组成和空间结构的研究却不多见, 需要引
起更多的关注。

黄梅秤锤树(Sinojackia huangmeiensis)为安息 香科秤锤树属(Sinojackia)植物, 是我国120种极小 种群野生植物之一。黄梅秤锤树的分布范围极其狭 窄, 目前所知该种仅分布于湖北省黄梅县下新镇钱 林村, 所处位置生态环境破坏严重, 生境孤立, 难 以与外界进行基因交流, 如果不加以保护将会面临 更高的灭绝风险。目前, 国内外学者已对黄梅秤锤 树的形态特征、繁育系统、遗传多样性和微尺度遗 传结构等进行了研究(Yao et al, 2007; 张金菊等, 2008; 阮咏梅等, 2012; Zhang et al, 2012; Zhao et al, 2016), 但主要集中在对该物种繁育和种群遗传学 特性的研究, 很少有对其所在群落中物种组成、空 间格局及关联性和萌菜繁殖的报道。而针对珍稀植 物, 尤其是极小种群野生植物, 研究其不同生长阶 段的空间关联性、种群大小结构和萌菜情况, 可以 更好地了解其种群更新动态和维持机制(周赛霞等, 2011; 刘海波等, 2014)。

本研究以当前唯一包含黄梅秤锤树野生个体 的植物群落为研究对象, 通过建立 1 ha的固定样地, 研究黄梅秤锤树野生植物群落物种组成、优势种的 径级结构、黄梅秤锤树的空间分布格局、种内与种 间空间关联性和萌菜特征, 分析黄梅秤锤树野生植 物群落的结构与动态, 旨在为该群落和黄梅秤锤树 的就地保护提供理论依据, 为迁地保护物种配置提 供参考, 并为该物种的动态变化规律研究积累资 料。

\section{研究区域概况}

研究地点位于湖北省黄梅县龙感湖国家级湿 地自然保护区内的下新镇钱林村次生阔叶林中 
$\left(29^{\circ} 59^{\prime} \mathrm{N}, 116^{\circ} 01^{\prime} \mathrm{E}\right)$, 海拔约31 m, 地势平坦。该区 域位于长江中游北岸, 大别山尾南缘, 属于亚热带 季风气候, 四季分明, 降水丰沛, 年平均气温 $17.1^{\circ} \mathrm{C}$, 最冷月 $\left(1\right.$ 月)平均气温 $4.3^{\circ} \mathrm{C}$; 最热月 $(7$ 月)平 均气温 $29.0^{\circ} \mathrm{C}$, 年降水量 $1,347.4 \mathrm{~mm}$ 。森林类型属于 次生阔叶林, 主要植物有黄梅秤锤树、麻栎(Quercus acutissima)、枸骨(Ilex cornuta)、朴树(Celtis sinensis)、枫香(Liquidambar formosana)、槲栋(Quercus aliena)、黄连木(Pistacia chinensis)、野桐(Mallotus tenuifolius)、大青(Clerodendrum cyrtophyllum)、樟 树(Cinnamomum camphora)和山胡椒(Lindera glau$c a)$ 等。该群落被局限在大约 2 ha的范围内, 周围被 龙感湖、池塘、稻田和旱田包围。该森林群落的形 成和干扰历史不详, 群落中最大个体树木是麻栎, 胸径为 $57 \mathrm{~cm}$ 。作为风水林, 林内人为活动相对频繁 但未见明显的人为砍伐痕迹。

\section{研究方法}

\section{1 样地设置与调查}

2017年5-6月，在下新镇钱林村次生阔叶林中, 参照CTFS (Centre for Tropical Forest Science)森林 动态样地建设技术规程(Condit, 1998)建立了面积为 1 ha的固定监测样地(图1)。用全站仪将样地划分为 25 个 $20 \mathrm{~m} \times 20 \mathrm{~m}$ 的连续样方, 每个样方的四角均用 水泥桩固定，每个样方又进一步分为 16 个 $5 \mathrm{~m} \times 5 \mathrm{~m}$ 的小样方, 记录样地内所有胸径 $\geq 1 \mathrm{~cm}$ 的木本植 物的学名、胸径和相对位置等, 挂牌, 以便进行永 久观察。针对有多个萌枝的个体, 记录萌枝数、胸 径或者高度; 以最大胸径或高度的萌枝为个体主 干, 其余为萌藥。物种名参考《中国植物志》 (中国 植物志编辑委员会, 2004) 和《湖北植物志》(傅书遐, 2003)。

除上述调查外, 还记录了样地内外所有黄梅秤 锤树的大小和相对位置, 针对胸径 $<1.0 \mathrm{~cm}$ 或高度 $\leq 1.3 \mathrm{~m}$ 的黄梅秤锤树，记录其高度。

\section{2 研究方法}

\subsection{1 群落结构}

重要值 $=($ 相对密度 + 相对频度 + 相对优势度 $) / 3$

相对密度 $=($ 某个种的株数 $/$ 所有种的总株数 $)$ $\times 100 \%$

相对频度 $=$ (某个种基于 $20 \mathrm{~m} \times 20 \mathrm{~m}$ 样方出现 的次数/所有种出现的总次数 $) \times 100 \%$
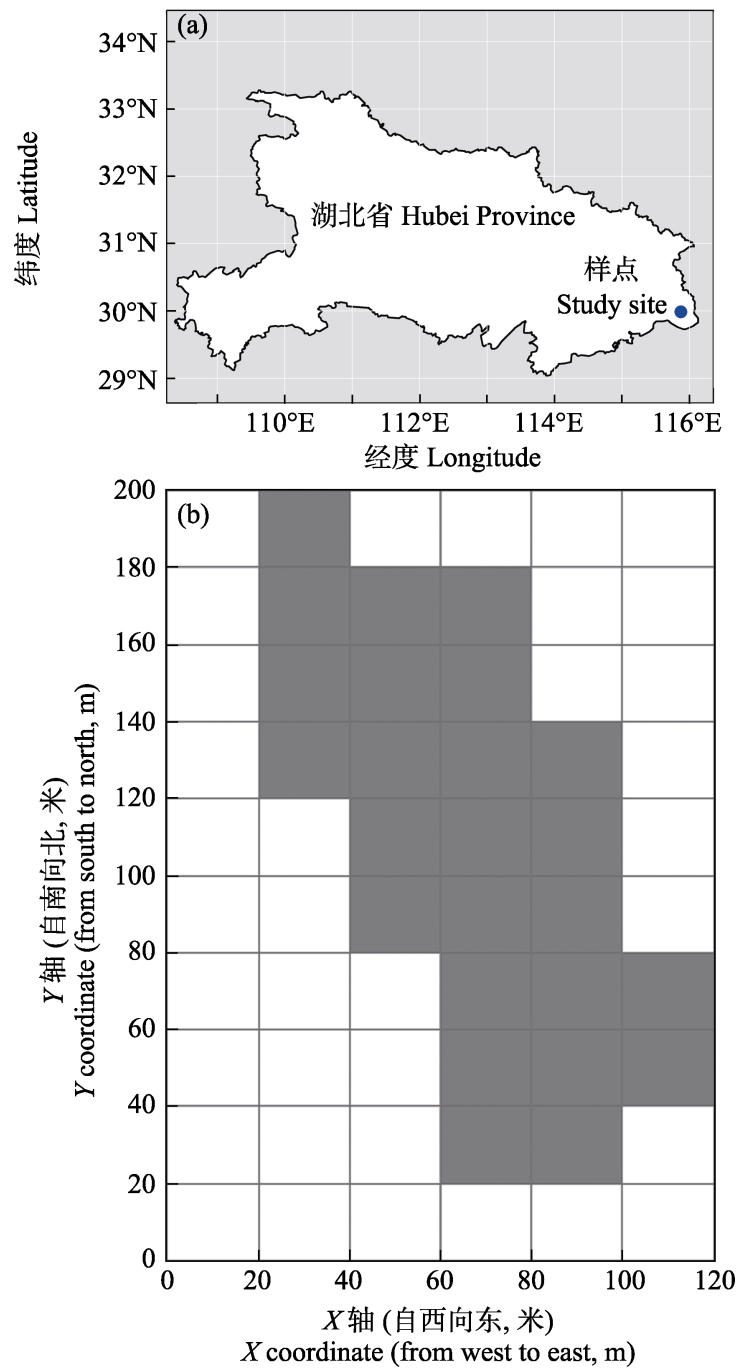

图1 1 ha 样地位置(a)和样地示意图(b)。灰色部分代表25 个 $20 \mathrm{~m} \times 20 \mathrm{~m}$ 的样方。

Fig. 1 Location and sketch map of the 1-ha plot. Grey area refers to the 25 subplots $(20 \mathrm{~m} \times 20 \mathrm{~m})$.

相对优势度 $=($ 某个种的胸高断面积 $/$ 所有种 的胸高断面积之和) $\times 100 \%$

\subsection{2 优势种种群大小级结构}

将胸径小于 $2.5 \mathrm{~cm}$ 的个体作为第一级, 之后以 $5 \mathrm{~cm}$ 作为径级大小间隔, 分别对 4 个优势种(麻栎、 枸骨、朴树和黄梅秤锤树)的所有个体进行分类，确 定不同大小级的比例，制作种群大小级结构图。

根据样地内林木胸径的实际情况, 将所有 DBH $\geq 1 \mathrm{~cm}$ 的个体分为 3 级: 小径木 $(1 \mathrm{~cm} \leq \mathrm{DBH}<7.5$ $\mathrm{cm}) 、$ 中径木 $(7.5 \mathrm{~cm} \leq \mathrm{DBH}<22.5 \mathrm{~cm})$ 和大径木 $(\mathrm{DBH} \geq 22.5 \mathrm{~cm})$ 。

\subsection{3 点格局分析}

利用单变量和双变量成对关联函数 g(r) (the 
pair-correlation function)研究黄梅秤锤树的空间分 布格局, 黄梅秤锤树与其他 3 个优势种(麻栎、枸骨 和朴树)的空间关联性, 以及黄梅秤锤树不同生长 阶段(幼苗、幼树和成年个体)的关联性。

$g(r)$ 函数的计算公式为: $g(r)=K^{\prime}(r) / 2 \pi r$

式中, $K^{\prime}(r)$ 为Ripley's $K$ 函数。利用单变量 $g_{1,1}(r)$ 函 数检测黄梅秤锤树的空间分布格局, 利用双变量 $\mathrm{g}_{1,2}(\mathrm{r})$ 函数检测黄梅秤锤树与其他 3 个优势种的空间 关联性和黄梅秤锤树幼苗、幼树和成年个体的关联 性(Ravento's et al, 2010)。运用Monte Carlo循环99 次，产生99\%的置信区间。

\subsection{4 更新特征}

萌葟率(ratio of sprout, RS)指某一 $20 \mathrm{~m} \times 20 \mathrm{~m}$ 的样方内黄梅秤锤树所有萌等数与该物种所有主 干数的比率(Wei et al, 2015)。相对幼苗密度(relative seedling density)指某一 $20 \mathrm{~m} \times 20 \mathrm{~m}$ 的样方内黄梅秤 锤树的幼苗数与该样方内该物种所有个体数的比 值。黄梅秤锤树的萌蓝数与母株胸径的关系, 相对 幼苗密度与萌菜率的关系, 以及它们与各样方内所 有物种的个体数(密度)和胸高断面积之和的关系用 Pearson相关系数度量。

\subsection{5 数据处理}

本文数据分析和作图使用 R 3.4.1、Excel和 SigmaPlot 12.0软件完成。

\section{3 结果}

\section{1 群落物种组成}

样地内共记录到胸径 $>1 \mathrm{~cm}$ 的木本植物 1,225 株，隶属于 21 科28属31种。其中属、种占优势的科 包括: 大戟科(3属3种)、豆科(2属2种)、马鞭草科(2 属2种)、桑科(2属2种)、榆科(2属2种)、樟科(2属2 种)、山矾科(1属3种)和壳斗科(1属2种)。其他科均 仅有 1 属 1 种。

样地内重要值 $\geq 1 \%$ 的物种共 17 种, 这些物种 的相对密度之和与相对胸高断面积之和分别为 95.18\%和 $98.06 \%$, 相对频度之和与重要值之和分别 是 $87.7 \%$ 和 $93.64 \%$ 。平均胸径最大的物种是麻栎, 为 $24.18 \mathrm{~cm}$, 有 212 株; 其次为枫香、槲栎、柿树 (Diospyros kaki)、黄连木和乌柏(Sapium sebiferum), 其平均胸径分别为 $16.00 \mathrm{~cm} 、 15.82 \mathrm{~cm} 、 11.69 \mathrm{~cm}$ 、 $9.74 \mathrm{~cm}$ 和 $8.91 \mathrm{~cm}$, 但这些物种个体数量都不超过 100 株(表1)。样地内所有 DBH $\geq 1 \mathrm{~cm}$ 的个体平均胸

表1 1 ha 样地内重要值 $\geq 1 \%$ 的物种的数量特征

Table 1 Quantitative characteristics of species with importance value $\geq 1 \%$ in the 1 -ha plot

\begin{tabular}{|c|c|c|c|c|}
\hline $\begin{array}{l}\text { 物种 } \\
\text { Species }\end{array}$ & $\begin{array}{l}\text { 多度 } \\
\text { Abundance }\end{array}$ & $\begin{array}{l}\text { 胸径 } \\
\mathrm{DBH}(\text { mean } \pm \mathrm{SE})(\mathrm{cm})\end{array}$ & $\begin{array}{l}\text { 胸高断面积 } \\
\text { Basal area (m²/ha) }\end{array}$ & $\begin{array}{l}\text { 重要值 } \\
\text { Importance value (\%) }\end{array}$ \\
\hline 麻栎 Quercus acutissima & 212 & $24.18 \pm 0.75$ & 11.99 & 27.40 \\
\hline 枸骨 Ilex cornuta & 282 & $5.25 \pm 0.26$ & 4.02 & 17.16 \\
\hline 朴树 Celtis sinensis & 125 & $6.01 \pm 0.61$ & 0.97 & 7.01 \\
\hline 黄梅秤锤树 Sinojackia huangmeiensis & 159 & $2.72 \pm 0.19$ & 0.26 & 6.45 \\
\hline 桷栋 Quercus aliena & 40 & $15.82 \pm 1.67$ & 1.15 & 4.84 \\
\hline 野桐 Mallotus tenuifolius & 77 & $2.75 \pm 0.14$ & 0.07 & 4.32 \\
\hline 黄连木 Pistacia chinensis & 27 & $9.74 \pm 1.46$ & 0.32 & 3.21 \\
\hline 大青 Clerodendrum cyrtophyllum & 40 & $1.97 \pm 0.12$ & 0.02 & 3.10 \\
\hline 樟树 Cinnamomum camphora & 24 & $7.89 \pm 1.83$ & 0.44 & 3.05 \\
\hline 乌柏 Sapium sebiferum & 30 & $8.91 \pm 1.02$ & 0.26 & 1.88 \\
\hline 白檀 Symplocos paniculata & 20 & $2.37 \pm 0.18$ & 0.01 & 1.62 \\
\hline 华山矾 Symplocos chinensis & 16 & $2.96 \pm 0.52$ & 0.02 & 1.52 \\
\hline 柿树 Diospyros kaki & 12 & $11.69 \pm 2.25$ & 0.18 & 1.27 \\
\hline 榆树 Ulmus pumila & 15 & $3.46 \pm 0.44$ & 0.02 & 1.23 \\
\hline 牡荆 Vitex negundo var. cannabifolia & 12 & $2.07 \pm 0.23$ & 0.01 & 1.13 \\
\hline 其他 Others & 59 & - & 0.42 & 6.36 \\
\hline 总计 Total & 1,225 & - & 21.64 & 100 \\
\hline
\end{tabular}


径为 $9.02 \mathrm{~cm}$ 。

重要值排在前4位的物种分别为麻柇、枸骨、 朴树和黄梅秤锤树。这 4 个物种相对密度之和为 $63.51 \%$, 相对优势度之和为 $79.62 \%$, 是该样地的主 要组成物种。其中, 麻栎不仅数量多, 而且相对优 势度达到 $55.38 \%$, 在群落组成中占有绝对优势, 是 该样地的建群种和优势种。枸骨在群落中的相对密 度最大, 但胸高断面积比麻栎要小很多, 主要位于 群落的灌木层, 是该样地的优势种。黄梅秤锤树虽 然在相对优势度 $(1.20 \%)$ 中不占优势, 但数量较大, 是群落中的主要组成树种之一。朴树的种群数量特 征与黄梅秤锤树类似, 虽然数量很多, 但多以小径 木形式存在，是群落中的主要组成树种之一。

黄梅秤锤树总共有 501 株, 其中胸径 $>1 \mathrm{~cm}$ 的 个体193株(样地中有159株), 幼苗308株, 产生萌蘖 的个体 123 株, 萌等数 356 株。样地中黄梅秤锤树的 幼苗和萌罯个体数较多, 说明种群的自然更新能够 正常进行, 并且靠种子和萌菜两种方式进行自然更 新。

\section{2 径级结构}

根据径级划分可知, 样地内大、中、小径木分 别占总株数的 $14.70 \% 、 18.12 \%$ 和 $67.18 \%$, 小径木个
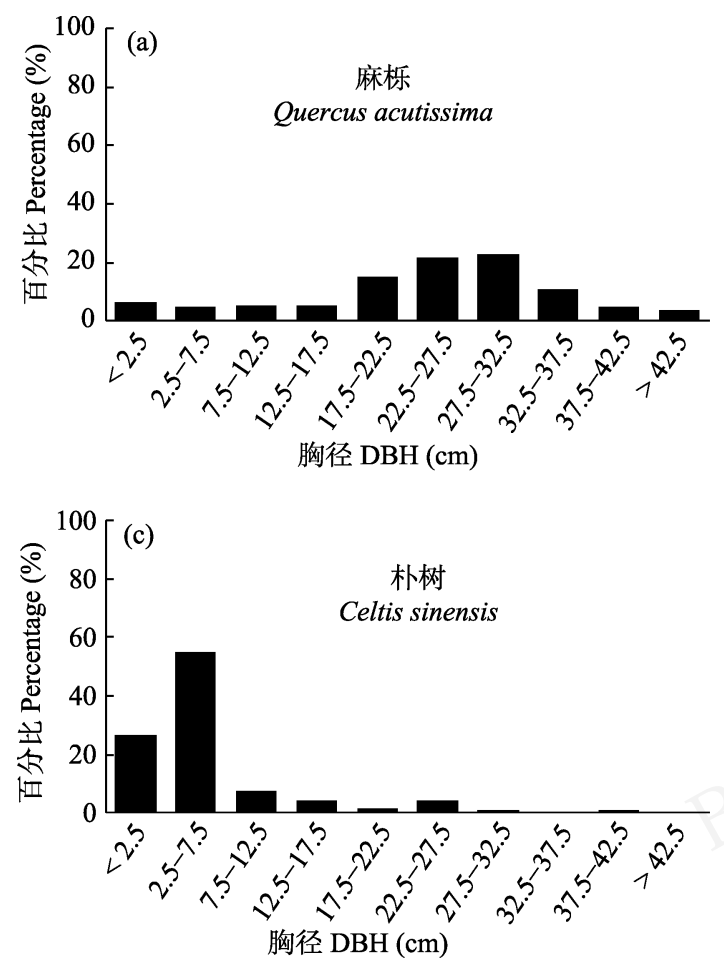

体所占比例较大，中径木个体和大径木个体所占比 例相似且较小(附录1)。不同等级径木的物种数量不 同，小径木所含物种数量最多，有29种，中径木次 之, 有 17 种, 大径木所含物种数量最少, 有 10 种。

重要值排在前 4 位的物种中, 麻栎的径级结构 分布呈单峰型, 个体主要集中在中径木和大径木, 小径木数量相对较少; 枸骨和朴树的径级结构分布 呈偏倒“J”型, 最小径级 $(<2.5 \mathrm{~cm})$ 个体数量相对较 多, 但个体数量最大值出现在 2.5-7.5 $\mathrm{cm}$ 的径级范 围; 黄梅秤锤树的径级结构分布呈现倒“J”型, 并且 大多数个体的 $\mathrm{DBH}<5 \mathrm{~cm}$ (图2)。总的来说，麻栎在 乔木层占优势, 但小径木较少, 随着演替的进行, 自然更新会受到影响; 枸骨和朴树种群在亚乔木层 占优势，自然更新良好; 黄梅秤锤树种群在灌木层 占优势, 由于其本身为灌木的特点, 所以小径木数 量多，而胸径 $>6.0 \mathrm{~cm}$ 的植株仅有 10 株。

\section{3 空间分布格局和种间关联}

黄梅秤锤树在样地的东南部聚集程度非常大; 朴树在样地西北部聚集明显; 麻栎和枸骨数量较多, 在整个样地中广泛分布。在黄梅秤锤树集中分布的 区域，其他物种分布相对较少(图3)。

黄梅秤锤树在 0-22 $\mathrm{m}$ 尺度上呈聚集分布,
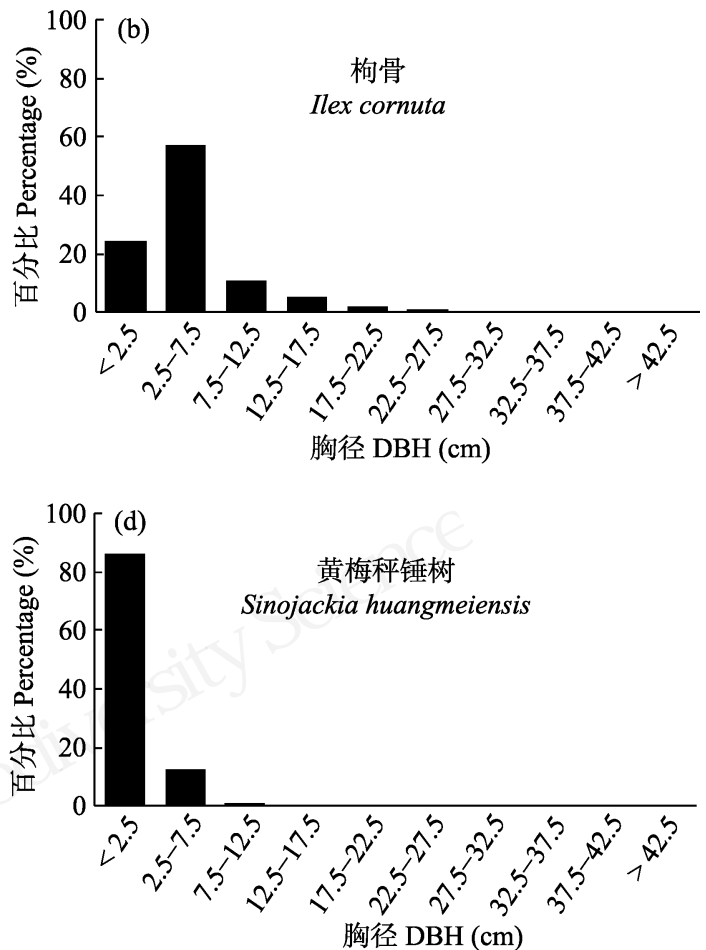

图2 1 ha样地内4个优势种的径级结构

Fig. 2 DBH size structure of the four dominant species in the 1-ha plot. DBH, diameter at breast height 

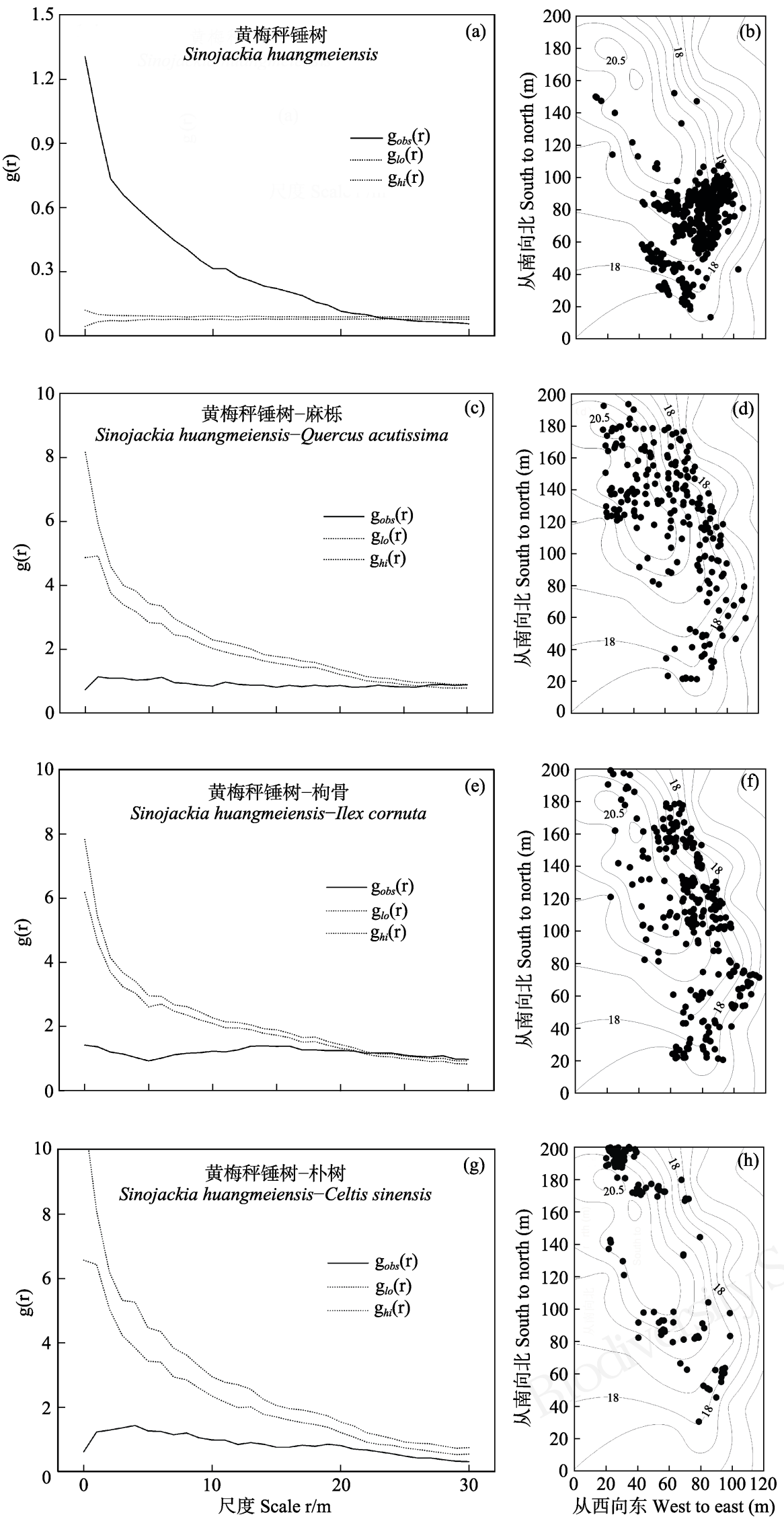

图3 黄秤锤树点格局分析(a)及其 与其他 3 个优势种的关联分析(c, e 和 $g$ )。图 $b, d, f$ 和h分别为黄梅秤锤 树、麻栋、枸骨和朴树的空间分布 图。图中黑色实线代表 $g(r)$ 在尺度 $\mathbf{r}$ 上的实际观测值, 细虚线代表模 拟99次形成的置信区间。点格局分 析中, 黑色实线高于(低于)置信区 间上限(下限)表示聚集分布(均匀 分布), 黑色实线位于置信区间之 内, 则表示随机分布。关联分析中, 黑色实线高于(低于)置信区间上限 (下限)表示正关联(负关联), 黑色 实线位于置信区间之内, 则表示无 关联。

Fig. 3 Point pattern analysis of Sinojackia huangmeiensis (a), correlation analyses between $S$. huangmeiensis and the other three dominant species (Quercus acutissima, Ilex cornuta, and Celtis sinensis) (c, e, and g), and point diagram of individual distribution of the four dominant species (b, d, f, and h). In the left panels, black solid lines indicate the values of the $g(r)$ function; thin dashed lines indicate the confidence envelope of the null model. In point pattern analysis (a), values of the $g(r)$ function above (below) the upper (lower) envelope indicate aggregated (regular), within envelope indicate random. In correlation analysis (c, e, g), values of the g(r) function above (below) the upper (lower) envelope indicate positive (negative) association, within envelope indicate no association. 

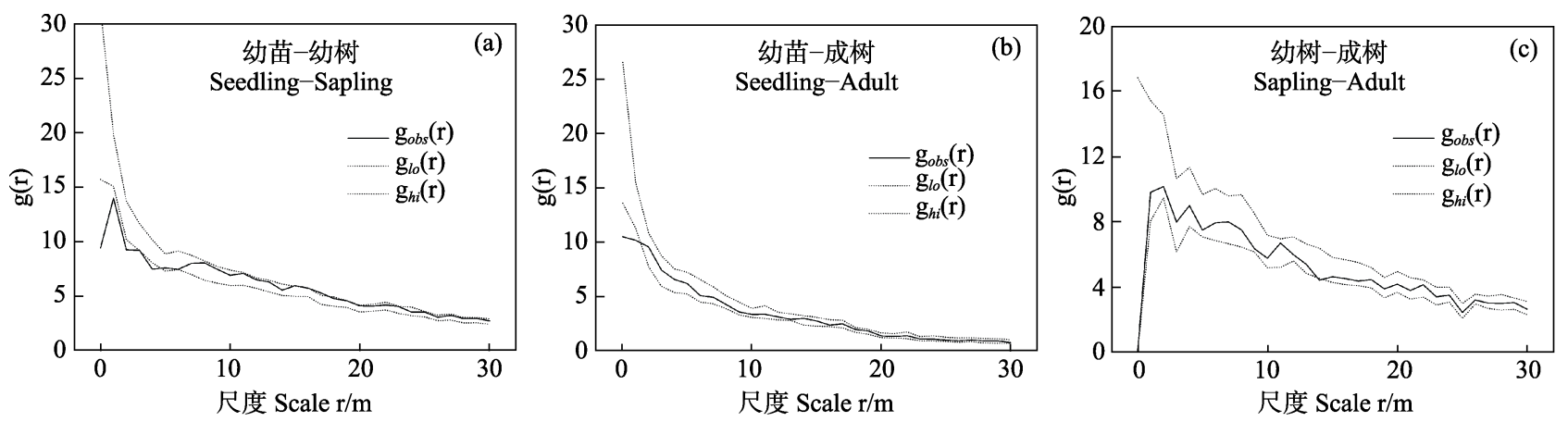

图4 黄梅秤锤树幼苗 $(\mathrm{DBH}<1 \mathrm{~cm})$ 、幼树 $(1 \mathrm{~cm} \leq \mathrm{DBH}<2.5 \mathrm{~cm})$ 和成年个体 $(\mathrm{DBH} \geq 2.5 \mathrm{~cm})$ 之间的关联分析。图中黑色实线 代表 $\mathbf{g}(\mathbf{r})$ 在尺度 $\mathbf{r}$ 上的实际观测值，细虚线代表模拟99次形成的置信区间。黑色实线高于(低于)置信区间上限(下限)表示正关 联(负关联)。黑色实线位于置信区间之内, 则表示无关联。

Fig. 4 Correlation analyses between seedling (DBH $<1 \mathrm{~cm})$, sapling $(1 \mathrm{~cm} \leq \mathrm{DBH}<2.5 \mathrm{~cm})$ and adult (DBH $\geq 2.5 \mathrm{~cm})$ of Sinojackia huangmeiensis. Black solid lines indicate the values of the $\mathrm{g}(\mathrm{r})$ function; thin dashed lines indicate the confidence envelope of the null model. Values of the g(r) function above (below) the upper (lower) envelope indicate positive (negative) association, within envelope indicate no association.

23-24 m尺度上呈随机分布, 25-30 m尺度上呈均匀 分布, 与麻栎在0-26 m尺度上呈负关联, 在其余研 究尺度上无关联; 与枸骨在0-21 m尺度上呈负关联, 在23-30 m尺度上呈正关联; 与朴树在所有研究尺 度上都呈负关联(图3)。这说明样地中的其他 3 个优势 种与黄梅秤锤树之间竞争激烈, 在空间上相互排斥。

\section{4 黄梅秤锤树的种内关联及更新特征}

黄梅秤锤树成树和幼苗在0-1 m尺度上呈负关 联, 其他研究尺度上无关联; 幼树和幼苗在0-2 m 和 $4 \mathrm{~m}$ 尺度上呈负相关, 在 $15 \mathrm{~m}$ 和 $17 \mathrm{~m}$ 尺度上呈正 相关, 其他尺度上无关联; 成树和幼树在 $14 \mathrm{~m}$ 尺度 上呈负关联，其他尺度上无关联(图4)。

黄梅秤锤树的萌榄数与母株胸径具有极显著 的正相关性 $(P<0.001)$, 母株胸径越大, 萌等数越 多(图5a)。其萌蘖率与相对幼苗密度具有极显著的 负相关性 $(P<0.001)$ (图5b)。

相对幼苗密度与样方内所有物种的个体数或 者胸高断面积之和呈现负相关，但不显著 $(P>0.05)$; 萌箵率与样方内所有物种的个体数或者胸高断面 积之和也呈现负相关, 但也不显著 $(P>0.05)$ 。

\section{4 讨论}

\section{1 物种组成和径级结构}

对黄梅秤锤树野生植物群落物种组成与群落 结构分析可知, 样地内共有木本植物21科28属31种 1,225株, 而同属于亚热带区域的山地原生林, 如五 峰后河的珍稀植物群落1 ha固定样地, 木本植物有
38科60属107种(田玉强等，2002); 同区域的次生林， 如湖南省大山冲森林公园次生混交林, 植物个体密 度为2,493株/ha(郭婧等, 2015)。相比之下, 黄梅秤锤 树野生植物群落物种丰富度和个体密度明显较低, 这说明地形以及人类活动干扰对样地中物种多样 性产生很大的影响。
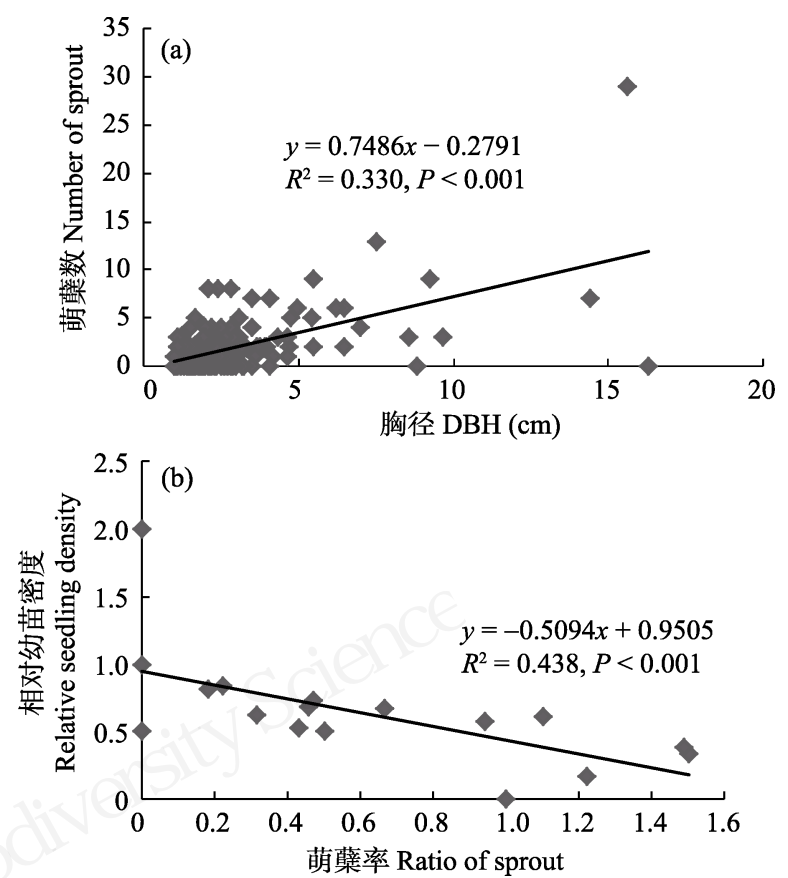

图5 黄梅秤锤树萌藍数与母株胸径的关系(a)和萌藍率与 相对幼苗密度的关系(b)

Fig. 5 Relationships between number of sprout and DBH (a), and relative seedling density and ratio of sprout (b). $\mathrm{DBH}$, diameter at breast height. 
样地内小径木个体占总体的 $67.18 \%$, 所占比例 较大, 说明群落更新状况良好, 但样地中枸骨、朴 树、黄梅秤锤树等灌木和小乔木数量比较多也是造 成小径级个体较多的原因之一。样地内优势种麻栋 的径级结构呈单峰型, 与乔木上层优势种的特征相 符, 但由于小径木比例较少, 随着演替的进行, 自 然更新可能会受到影响。枸骨、朴树和黄梅秤锤树 的径级结构呈“J”型或倒“J”型分布，小径木个体较 多, 一方面说明种群自然更新良好, 另一方面是由 于其自身灌木或小乔木的生物学特性决定的。胸径 最大的物种为麻柇 $(57.00 \mathrm{~cm})$, 样地所有木本植物 $(\mathrm{DBH} \geq 1 \mathrm{~cm})$ 的平均胸径为 $9.02 \mathrm{~cm}$, 远大于同属于 亚热带的天童山样地 $(5.66 \mathrm{~cm})$ 和古田山样地(5.21 cm) (宋永昌等, 2015), 这是因为虽然小径木的比例 较高, 但胸径 $20 \mathrm{~cm}$ 以上的大径木占 $14.70 \%$, 所占 比例相对较高。这说明该区域的保护确实有了一定 效果, 现存的物种能够进行正常生长, 但随着演替 的进行, 中径木向大径木的补充可能会有所减少。

\section{2 空间分布格局和种间关联}

黄梅秤锤树的空间分布整体上随着尺度的增 加呈现出先聚集分布、后随机分布、最后均匀分布 的特征。种群在小尺度上呈聚集分布与其种子的扩 散限制(Seidler \& Plotkin, 2006)和自身生物学特性 有关(韩有志和王政权, 2002)。黄梅秤锤树的种子个 体大且重, 扩散能力有限, 再加上萌生枝多, 因此 在小尺度上呈聚集分布。同时, 作为小径木, 往往 具有较强的聚集能力, 在小尺度上争夺空间资源, 种内竞争激烈, 当尺度扩大到一定范围时, 竞争减 弱, 最终表现为随机分布(张毓涛等, 2011)。此外, 负密度制约效应使个体数量减少, 种群分布的聚集 程度减弱, 也逐渐形成随机或均匀分布(Wright, 2002; 祝燕, 2009)。

黄梅秤锤树与其他 3 个优势种(麻栎、枸骨、朴 树)在空间上主要呈负关联性。在黄梅秤锤树集中分 布的东南部区域，其他 3 个优势种分布较少。这可能 是因为某一物种首先占据了林下生态位, 影响了其 他物种的进入, 产生了生态位的分化, 环境资源得 到更加充分的利用(徐丽娜和金光泽, 2012)。但同时, 黄梅秤锤树与其他优势种在种群边缘的竞争, 使黄 梅秤锤树的生长以及种群分布范围的扩大受到了 影响。物种间的竞争较为激烈, 说明物种组成和群 落结构还未达到稳定阶段(郭圭金等, 2011)。因此,
在今后的管理过程中，可采取择伐等手段，人为促 进天然更新与扩散。

\section{3 更新策略和种内关联}

木本植物可以通过种子繁殖和萌藥繁殖进行 自然更新, 不同的繁殖策略与自身生物学特性和环 境因素相关(陈沐等, 2007; Bellingham \& Sparrow, 2009)。萌菒作为植物营养繁殖的方式之一，可以使 植物在逆境下产生较为稳定的“种源”(贺金生等, 1998)。但仅仅通过萌菜形式很难扩大植物的分布区, 因此, 自然状态下还需要通过种子进行实生苗的更 新(贺金生等, 1999)。本研究中，黄梅秤锤树实生幼 苗和萌雀个体数都较多, 说明同时用种子和萌菜两 种方式进行繁殖, 通过萌藥更新利于抵抗干扰和不 利的环境，通过实生苗更新来扩大分布区域，使得 种群的自然更新能够正常进行。

黄梅秤锤树萌藥率与相对幼苗密度具有极显 著的负相关性，这可能是因为在繁殖过程中，如果 将更多的养分分配给分㭗，则分配到种子中的养分 减少，种子产量或质量下降进而导致幼苗数量减少, 可能意味着黄梅秤锤树在有性繁殖和营养繁殖之 间的权衡。有研究表明, 植物萌等能力与样方内所 有个体的胸高断面积之和具有显著的负相关性, 这 是因为在大径级个体较多的样地中，资源的有效性 抑制了植物的萌䔞能力(郭屹立等, 2015)。然而, 在 我们的研究中, 不论是黄梅秤锤树的相对幼苗密度 还是萌临率, 与样方内的所有物种的个体数或者胸 高断面积之和均呈现不显著的负相关关系。此外，黄 梅秤锤树的萌薬数与母株的胸径具有极显著的正 相关性, 这可能是因为样地中以小径级的个体为主, 胸径较大的植株更利于获得资源而提高萌蓝能力。

黄梅秤锤树种群不同发育阶段的关联性分析 表明, 幼苗与幼树和成树在小尺度上均呈负关联, 在大尺度上关联性不显著，而成树和幼树在整体上 关联性不显著。这说明成树和幼树与幼苗争夺资源, 并且幼苗的更新并非在母树下发生，而是在距母树 一定范围外进行。这可能是因为, 落叶树种耐阴性 较差, 靠近母树的地方光线较差, 不利于种子的萌 发, 实生苗较少(何东等, 2009), 而母树附近的林间 空隙反而能够满足种子萌发的需求, 幼苗在此处相 互庇护聚集生长(张震等, 2010)。但随着个体的生长, 由于负密度制约效应，可能会使聚集在一起的幼苗 数量减少, 影响了幼苗向成年个体的过渡。成树和 
幼树在整体上关联性不显著，可能是因为它们的空 间距离较远，独立竞争及抵抗性都较强，不易受到 影响(吴初平等, 2018)。因此, 在今后的管理中, 可 以对样地进行适当择伐以增加光照, 为幼苗的生长 提供适宜环境。对于聚集生长在一起的幼苗和幼树, 在保证能够相互庇护抵御环境危害的基础上，进行 适当移植, 以降低幼苗与幼苗之间以及幼树与幼苗 之间的资源竞争。

致谢：野外调查得到龙感湖国家级湿地自然保护区 管理局和黄冈师范学院的大力支持，谨致谢忱!

\section{参考文献}

Aerts R, Overtveld KV, Haile M, Hermy M, Deckers J, Muys B (2006) Species composition and diversity of small Afromontane forest fragments in northern Ethiopia. Plant Ecology, 187, 127-142.

Bellingham PJ, Sparrow AD (2009) Multi stemmed trees in montane rain forests: Their frequency and demography in relation to elevation, soil nutrients and disturbance. Journal of Ecology, 97, 472-483.

Chen M, Cao M, Lin LX (2007) Research advances in regeneration of woody plants by sprouting. Chinese Journal of Ecology, 26, 1114-1118. (in Chinese with English abstract) [陈沐, 曹敏, 林露湘 (2007) 木本植物萌生更新研究进 展. 生态学杂志, 26, 1114-1118.]

Condit R (1998) Tropical Forest Census Plots. Springer-Verlag, Berlin.

Da LJ, Yang YC, Song YC (2004) Population structure and regeneration types of dominant species in an evergreen broadleaved forest in Tiantong National Forest Park, Zhejiang, China. Acta Phytoecologica Sinica, 28, 376-384. (in Chinese with English abstract) [达良俊, 杨永川, 宋永昌 (2004) 浙江天童国家森林公园常绿阔叶林主要组成种的 种群结构及更新类型. 植物生态学报, 28, 376-384.]

Dale MRT (1999) Spatial Pattern Analysis in Plant Ecology. Cambridge University Press, Cambridge.

Editorial Committee of Flora of China (2004) Flora of China. Science Press, Beijing. (in Chinese) [中国植物志编辑委员 会 (2004) 中国植物志. 科学出版社, 北京.]

Fu SX (2003) Flora Hubeiensis. Hubei Science \& Technology Press, Wuhan. (in Chinese) [傅书遐 (2003) 湖北植物志. 湖北科学技术出版社, 武汉.]

Gao FY, Zhao CZ, Zhuo Ma LC (2014) Spatial distribution and spatial association of Stellera chamaejasme population in the different altitude in degraded alpine grassland. Acta Ecologica Sinica, 34, 605-612. (in Chinese with English abstract) [高福元, 赵成章, 卓马兰草 (2014) 高寒退化草地 不同海拔梯度狼毒种群分布格局及空间关联性. 生态学
报, 34, 605-612.]

Guo J, Yu LH, Fang X, Xiang WH, Deng XW, Lu X (2015) Litter production and turnover in four types of subtropical forests in China. Acta Ecologica Sinica, 35, 4668-4677. (in Chinese with English abstract) [郭婧, 喻林华, 方晰, 项文 化, 邓湘雯, 路翔 (2015) 中亚热带4种森林凋落物量、组 成、动态及其周转期. 生态学报, 35, 4668-4677.]

Guo YL, Wang B, Xiang WS, Ding T, Lu SH, Wen SJ, Huang FZ, Li DX, Li XK (2015) Sprouting characteristics of tree species in $15-\mathrm{hm}^{2}$ plot of northern tropical karst seasonal rain forest in Nonggang, Guangxi, southern China. Chinese Journal of Ecology, 34, 955-961. (in Chinese with English abstract) [郭屹立，王斌，向悟生，丁涛，陆树华，文淑均， 黄甫昭, 李冬兴, 李先琨 (2015) 弄岗北热带喀斯特季节 性雨林 $15 \mathrm{hm}^{2}$ 样地木本植物萌生特征. 生态学杂志, 34, 955-961.]

Guo YX, Kang B, Li G, Wang DX, Yang GH, Wang DW (2011) Species composition and point pattern analysis of standing trees in secondary Betula albo-sinensis forest in Xiaolongshan of west Qinling Mountains. Chinese Journal of Applied Ecology, 22, 2574-2580. (in Chinese with English abstract) [郭圭金金, 康冰, 李刚, 王得祥, 杨改河, 王 大伟 (2011) 小陇山红桦次生林物种组成与立木的点格 局分析. 应用生态学报, 22, 2574-2580.]

Han YZ, Wang ZQ (2002) Spatial heterogeneity and forest regeneration. Chinese Journal of Applied Ecology, 13, 615-619. (in Chinese with English abstract) [韩有志, 王政 权 (2002) 森林更新与空间异质性. 应用生态学报, 13, 615-619.]

He D, Wei XZ, Li LF, Jiang MX, Yang JY, Yu J (2009) Population structure and dynamics of Cercidiphyllum japonicum in riparian zones of the Shennongjia Mountainous Region, Central China. Chinese Journal of Plant Ecology, 33, 469-481. (in Chinese with English abstract) [何东, 魏新增, 李连发, 江明喜, 杨敬元, 喻杰 (2009) 神农架山地河岸 带连香树的种群结构与动态. 植物生态学报, 33, 469-481.]

He JS, Chen WL, Liu F (1998) Study on the sprouting process of Fagus engleriana in Shennongjia Mountains. Acta Phytoecologica Sinica, 22, 385-391. (in Chinese with English abstract) [贺金生，陈伟烈，刘峰 (1998) 神农架地区米心 水青冈萌枝过程的研究. 植物生态学报, 22, 385-391.]

He JS, Liu F, Chen WL, Chen LZ (1999) History of disturbance and regeneration strategies of Fagus engleriana and Quercus aliena var. acuteserrata forests in Shennongjia, Hubei Province. Acta Botanica Sinica, 41, 887-892. (in Chinese with English abstract) [贺金生, 刘峰, 陈伟烈, 陈 灵芝 (1999) 神农架地区米心水青冈林和锐齿葪栎林群 落干扰历史及更新策略. 植物学报, 41, 887-892.]

John R, Dalling JW, Harms KE, Yavitt JB, Stallard RF, Mirabello M, Hubbell SP, Valencia R, Navarrete H, Foster RB (2007) Soil nutrients influence spatial distributions of tropical tree species. Proceedings of the National Academy of 
Science, USA, 104, 864-869.

Liang S, Xu H, Lin JY, Li YD, Lin MX (2014) Spatial distribution pattern of the dominant species Gironniera subaequalis in tropical montane rainforest of Jianfengling, Hainan Island, China. Chinese Journal of Plant Ecology, 38, 1273-1282. (in Chinese with English abstract) [梁爽, 许涵, 林家怡, 李意德, 林明献 (2014) 尖峰岭热带山地雨林优 势树种白颜树空间分布格局. 植物生态学报, 38, 1273-1282.]

Liu HB, Wang QG, Lu JM, Xu YZ, Lu ZJ, Qiao XJ, Bao DC, Guo YL, Meng HJ, Jiang MX (2014) Root-sprouting ability in an evergreen and deciduous broad-leaved mixed forest. Chinese Science Bulletin, 59, 3491-3498. (in Chinese with English abstract) [刘海波, 王庆刚, 路俊盟, 徐耀粘, 卢志 军, 乔秀娟, 鲍大川, 郭屹立, 孟红杰, 江明喜 (2014) 八大公山常绿落叶阔叶混交林根萌能力. 科学通报, 59, 3491-3498.]

Liu MX (2017) Spatial distribution and spatial association of Potentilla fruticosa populations on different slope aspects in subalpine meadow. Chinese Journal of Applied Ecology, 28, 1817-1823. (in Chinese with English abstract) [刘旻霞 (2017) 亚高寒草甸不同坡向金露梅种群的空间分布格局 及空间关联. 应用生态学报, 28, 1817-1823.]

Liu YH, Liu JF, He ZS, Hong W, Feng XP, Ya ZC (2017) Pinus taiwanensis community composition and structure based on fixed sample Daiyun Mountain. Guihaia, 37, 881-890. (in Chinese with English abstract) [刘艳会, 刘金福, 何中 声, 洪伟, 冯雪萍, 崖佐朝 (2017) 基于戴云山固定样地 黄山松群落物种组成与结构研究.广西植物, 37, 881-890.]

Nong Y, Zheng L, Jia HY, Lu LH, Huang DW, Huang BH, Lei LQ (2015) Community characteristics and spatial distribution of dominant tree species in a secondary forest of Daqing Mountains, southwestern Guangxi, China. Biodiversity Science, 23, 321-331. (in Chinese with English abstract) [农 友, 郑路, 贾宏炎, 卢立华, 黄德卫, 黄柏华, 雷丽群 (2015) 广西大青山次生林的群落特征及主要乔木种群的 空间分布格局. 生物多样性, 23, 321-331.]

Omelko A, Ukhvatkina O, Zhmerenetsky A, Sibirina L, Petrenko T, Bobrovsky M (2018) From young to adult trees: How spatial patterns of plants with different life strategies change during age development in an old-growth Korean pine-broadleaved forest. Forest Ecology and Management, 411, 46-66.

Ravento's J, Wiegand T, Luis MD (2010) Evidence for the spatial segregation hypothesis: A test with nine-year survivorship data in a Mediterranean shrubland. Ecology, 91, 2110-2120.

Ripley BD (1977) Modeling spatial patterns. Journal of the Royal Statistical Society: Series B (Statistical Methodology), 39, 172-212.

Ruan YM, Zhang JJ, Yao XH, Ye QG (2012) Genetic diversity and fine-scale spatial genetic structure of different lifehisto- ry stages in a small, isolated population of Sinojackia huangmeiensis (Styracaceae). Biodiversity Science, 20, 460-469. (in Chinese with English abstract) [阮咏梅, 张金 菊, 姚小洪, 叶其刚 (2012) 黄梅秤锤树孤立居群的遗传 多样性及其小尺度空间遗传结构. 生物多样性, 20, 460-469.]

Seidler TG, Plotkin JB (2006) Seed dispersal and spatial pattern in tropical trees. PLoS Biology, 4, 2132-2137.

Song YC, Yan ER, Song K (2015) Synthetic comparison of eight dynamics plots in evergreen broadleaf forests, China. Biodiversity Science, 23, 139-148. (in Chinese with English abstract) [宋永昌, 阎恩荣, 宋坤 (2015) 中国常绿阔叶林 8 大动态监测样地植被的综合比较. 生物多样性, 23, 139-148.]

Tang CQ, Yang YC, Ohsawa M, Momohara A, Mu JZ, Robertson K (2013) Survival of a tertiary relict species, Liriodendron chinese (Magnoliaceae), in southern China, with special reference to village fengshui forests. American Journal of Botany, 100, 2112-2119.

Tian YQ, Li X, Hu LL, Huang HD, Jiang MX (2002) The characteristics of tree layer structure of the rare plant community in Houhe Nature Reserve. Journal of Wuhan Botanical Research, 20, 443-448. (in Chinese with English abstract) [田玉强, 李新, 胡理乐, 黄汉东, 江明喜 (2002) 后河自 然保护区珍稀濒危植物群落乔木层结构特征. 武汉植物 学研究, 20, 443-448.]

Tilman D, Reich PB, Knops JMH (2006) Biodiversity and ecosystem stability in a decade-long grassland experiment. Nature, 441, 629-632.

Wang L, Sun QW, Hao ZY, Tian SN, Zhang SS, Chen YK, Zhang XP (2010) Point pattern analysis of different age-class Taxus chinensis var. mairei individuals in mountainous area of southern Anhui Province. Chinese Journal of Applied Ecology, 21, 272-278. (in Chinese with English abstract) [王否, 孙启武, 郝朝运, 田胜尼, 张姗姗, 陈一锟, 张小平 (2010) 皖南山区南方红豆杉种群不同龄级立木 的点格局分析. 应用生态学报, 21, 272-278.]

Wei X, Wu H, Meng H, Pang C, Jiang M (2015) Regeneration dynamics of Euptelea pleiospermum along latitudinal and altitudinal gradients: Trade-offs between seedling and sprout. Forest Ecology and Management, 353, 232-239.

Wiegand T, Gunatilleke S, Gunatilleke N (2007) Species association in a heterogeneous Sri Lankan dipterocarp forest. The American Naturalist, 170, E77-E95.

Wright JS (2002) Plant diversity in tropical forest: A review of mechanisms of species coexistence. Oecologia, 130, 1-14.

Wu CP, Yuan WG, Sheng WX, Huang YJ, Chen QB, Shen AH, Zhu JR, Jiang B (2018) Spatial distribution patterns and association of tree species in typical natural secondary forest communities in Zhejiang Province. Acta Ecologica Sinica, 38, 537-549. (in Chinese with English abstract) [吴初平, 袁位高, 盛卫星, 黄玉洁, 陈庆标, 沈爱华, 朱锦茹, 江 波 (2018) 浙江省典型天然次生林主要树种空间分布格 
局及其关联性. 生态学报, 38, 537-549.]

Xie CQ, Tian MX, Zhao ZR, Zheng WL, Wang GY (2015) Spatial point pattern analysis of Abies georgei var. smithii in forest of Sygera Mountains in southeast Tibet, China. Chinese Journal of Applied Ecology, 26, 1617-1624. (in Chinese with English abstract) [解传奇, 田民霞, 赵忠瑞, 郑 维列, 王国严 (2015) 西藏色季拉山急尖长苞冷杉种群 点格局分析. 应用生态学报, 26, 1617-1624.]

Xu LN, Jin GZ (2012) Species composition and community structure of a typical mixed broadleaved-Korean pine (Pinus koraiensis) forest plot in Liangshui Nature Reserve, Northeast China. Biodiversity Science, 20, 470-481. (in Chinese with English abstract) [徐丽娜, 金光泽 (2012) 小兴安岭 凉水典型阔叶红松林动态监测样地: 物种组成与群落结 构. 生物多样性, 20, 470-481.]

Yang YC, Yuan XZ, Li BZ, Sun R, Wang Q (2007) Characteristics and significance of the remnant evergreen broad-leaved forest in the urban area of Chongqing, China. Biodiversity Science, 15, 247-256. (in Chinese with English abstract) [杨 永川, 袁兴中, 李百战, 孙荣, 王强 (2007) 重庆都市区 残存常绿阔叶林的群落特征及其意义. 生物多样性, 15, 247-256.]

Yao XH, Ye QG, Ge JW, Kang M, Huang HW (2007) A new species of Sinojackia (Styracaceae) from Hubei, Central China. Novon, 17, 138-140.

Zhang JJ, Ye QG, Gao PX, Yao XH (2012) Genetic footprints of habitat fragmentation in the extant populations of Sinojackia (Styracaceae): Implications for conservation. Botanical Journal of the Linnean Society, 170, 232-242.

Zhang JJ, Ye QG, Yao XH, Zhang SJ, Huang HW (2008) Preliminary studies on the floral biology, breeding system and reproductive success of Sinojackia huangmeiensis, an endangered plant in a fragmented habitat in Hubei Province, China. Journal of Plant Ecology (Chinese Version), 32, 743-750. (in Chinese with English abstract) [张金菊, 叶其 刚, 姚小洪, 张胜菊, 黄宏文 (2008) 片断化生境中濒危 植物黄梅秤锤树的开花生物学、繁育系统与生殖成功的 因素. 植物生态学报, 32, 743-750.]

Zhang YT, Li JM, Chang SL, Li X, Lu JJ (2011) Spatial distribution pattern of Picea schrenkiana var. tianshanica popu- lation and its relationships with topographic factors in middle part of Tianshan Mountain. Chinese Journal of Applied Ecology, 22, 2799-2806. (in Chinese with English abstract) [张毓涛, 李吉玫, 常顺利, 李翔, 芦建江 (2011) 天山中 部天山云杉种群空间分布格局及其与地形因子的关系. 应用生态学报, 22, 2799-2806.]

Zhang Z, Liu P, Ding Y, Liu LM (2010) Distribution patterns of Picea schrenkiana var. tianshanica populations at different developmental stages in the western Tianshan Mountain, northwestern China. Journal of Beijing Forestry University, 32(3), 75-79. (in Chinese with English abstract) [张震, 刘 萍, 丁易, 刘黎明 (2010) 天山云杉林不同发育阶段种群 分布格局研究. 北京林业大学学报, 32(3), 75-79.]

Zhao J, Tong Y, Ge T, Ge J (2016) Genetic diversity estimation and core collection construction of Sinojackia huangmeiensis based on novel microsatellite markers. Biochemical Systematics and Ecology, 64, 74-80.

Zhou SX, Jiang MX, Bao DC, Tao M, Huang HD (2011) Population structure and regenerative characteristics of major tree species of rare plant community in Houhe Nature Reserve. Guihaia, 31, 209-216. (in Chinese with English abstract) [周赛霞, 江明喜, 鲍大川, 陶敏, 黄汉东 (2011) 后河自然保护区珍稀植物群落结构及更新特性. 广西植 物, 31, 209-216.]

Zhu Y (2009) The Prevalence of Density Dependence in Gutianshan Subtropical Evergreen Broadleaved Forest, China. $\mathrm{PhD}$ dissertation, Institute of Botany, Chinese Academy of Sciences, Beijing. (in Chinese with English abstract) [祝燕 (2009) 古田山亚热带常绿阔叶林密度制约普遍性研究. 博士学位论文, 中国科学院植物研究所, 北京.]

Zhu Y, Bai F, Liu HF, Li WC, Li L, Li GQ, Wang SZ, Sang WG (2011) Population distribution patterns and interspecific spatial associations in warm temperate secondary forests, Beijing. Biodiversity Science, 19, 252-259. (in Chinese with English abstract) [祝燕, 白帆, 刘海丰, 李文超, 李亮, 李 广起, 王顺忠, 桑卫国 (2011) 北京暖温带次生林种群分 布格局与种间空间关联性. 生物多样性, 19, 252-259.]

(责任编委: 王希华 责任编辑: 问文杰)

\section{附录 Supplementary Material}

附录1 1 ha样地内DBH $\geq 1 \mathrm{~cm}$ 木本植物径级分布

Appendix1 Size-class distribution of woody plants $(\mathrm{DBH} \geq 1 \mathrm{~cm})$ in the 1-ha plot http://www.biodiversity-science.net/fileup/PDF/2018055-1.pdf 
王世制, 吴浩, 刘梦婷, 张佳金金, 刘检明, 孟红杰, 徐耀粘, 乔秀娟, 魏新增, 卢志军, 江明喜. 极小种群野 生植物黄梅秤锤树群落结构与动态. 生物多样性, 2018, 26 (7): 749-759.

http://www.biodiversity-science.net/CN/10.17520/biods.2018055

附录1 1 ha样地内DBH $\geq 1 \mathrm{~cm}$ 木本植物径级分布

Appendix1 Size-class distribution of woody plants $(\mathrm{DBH} \geq 1 \mathrm{~cm})$ in the 1-ha plot

\begin{tabular}{lllll}
\hline 径级范围 & $\begin{array}{l}\text { 个体数 } \\
\text { No. of individuals for } \\
\text { DBH class }(\mathrm{cm})\end{array}$ & $\begin{array}{l}\text { 等级 } \\
\text { Rank }\end{array}$ & $\begin{array}{l}\text { 各等级株数 } \\
\text { No. of individuals for each } \\
\text { rank }\end{array}$ & $\begin{array}{l}\text { 各等级比例 } \\
\text { Rate of each rank (\%) }\end{array}$ \\
\hline$<2.5$ & 378 & 小径木 & 823 & 67.18 \\
$2.5-7.5$ & 445 & & & 18.12 \\
$7.5-12.5$ & 90 & 中径木 & 222 & \\
$12.5-17.5$ & 67 & & & \\
$17.5-22.5$ & 65 & & & \\
$22.5-27.5$ & 71 & 大径木 & 180 & \\
$27.5-32.5$ & 63 & & & \\
$32.5-37.5$ & 26 & & & \\
$37.5-42.5$ & 12 & & & \\
$>42.5$ & 8 & & & \\
\hline
\end{tabular}

